Journal homepage:

http://www.jurnalmetal.or.id/index.php/jmi

p-issn : $0126-3463$

e-issn : $2548-673 \mathrm{X}$

\title{
RANCANG BANGUN PENDINGIN MEDIA KALIBRASI THERMOHYGROMETER
} BERBASIS PELTIER

\section{DESIGN OF COOLER OF THERMOHYGROMETER CALIBRATION MEDIUM BASED PELTIER}

\author{
Trismiyati, Nur Islami Dewi, Rurut Amiru \\ Balai Besar Logam dan Mesin (BBLM), Kementerian Perindustrian \\ Jl. Sangkuriang No. 12 Kota Bandung 40135 \\ Email: trismiyati@kemenperin.go.id,ab_mapo@yahoo.com,rurut.amiru@yahoo.com
}

\begin{abstract}
Abstrak
Media kalibrasi thermohygrometer memerlukan pendingin untuk mencapai temperatur $20^{\circ} \mathrm{C}$. Pendingin ruangan digunakan untuk mencapai temperatur tersebut dengan waktu sekitar 12 jam pada malam. Untuk itu dilakukan perancangan sistem pendingin dengan peltier sebagai alternatif pengganti pendinginan dengan pendingin ruangan. Tahapan penelitian adalah memperhitungkan beban termal, merancang sistem pendingin dengan peltier dan menganalisa respon waktu. Hasil pengujian menunjukkan pendinginan dengan konfigurasi yang terdiri dari radiator $\mathrm{C}$ yang terhubung dengan Radiator B, 5 modul peltier ET-63-10-13 dan 3 modul peltier ET-127-14-11, heat sink A dan kipas serta pompa dan coolant menghasilkan temperatur media terendah. Media kalibrasi thermohygrometer dapat mencapai temperatur $23,4^{\circ} \mathrm{C}$ dalam waktu 118 menit dengan temperatur ruangan $27,3{ }^{\circ} \mathrm{C}$.
\end{abstract}

Kata kunci: media, temperatur, peltier, pendingin, waktu

\begin{abstract}
The thermohygrometer calibration medium requires a coolant to reach a temperature of $20{ }^{\circ} \mathrm{C}$. The air conditioner is used to reach the temperature about 12 hours at night. For that done cooling system design with peltier as an alternative to cooling with air conditioner. The research stages are to calculate the thermal load, design the cooling system with peltier and analyze the response time. The test results showed cooling with a configuration consisting of a radiator $C$ connected to Radiator $B, 5$ ET-63-10-13 peltier modules and 3 ET-127-14-11 peltier modules, heat sink A and fan and pump and coolant to produce the lowest temperature of medium. The thermohygrometer calibration medium can reach a temperature of $23.4^{\circ} \mathrm{C}$ in 118 minutes with a room temperature of $27.3^{\circ} \mathrm{C}$.
\end{abstract}

Keywords: medium, temperature, peltier, cooler, time

\section{PENDAHULUAN}

Media kalibrasi thermohygrometer memerlukan sistem pendingin untuk memenuhi kebutuhan temperatur pengukuran. Sistem pendingin yang tersedia saat ini menggunakan pendinginan yang berasal dari luar media yaitu AC ruangan. Pendinginan media kalibrasi thermohygrometer dengan AC ruangan ini dapat mencapai $20{ }^{\circ} \mathrm{C}$ dengan waktu sekitar 12 jam pada malam hari dengan temperatur lingkungan sebagai temperatur awal.

Penelitian bertujuan merancang sistem pendingin dengan peltier pada media kalibrasi thermohygrometer. Penelitian dibatasi dengan penggunaan peltier $5 \mathrm{~V}$ dan/atau peltier $12 \mathrm{~V}$, heat sink yang ada di pasaran, kipas, radiator, coolant, dan pompa.

Penelitian tentang pendingin berbasis peltier telah banyak dilakukan. Berikut beberapa penelitian yang telah dilakukan peneliti. Mobil yang di parkir di tempat terbuka di bawah sinar matahari akan mengalami peningkatan temperatur di dalam kabin hingga $52,4{ }^{\circ} \mathrm{C}$ (Priyambada 2012). Hal ini disebabkan konduksi terhadap badan mobil, konveksi di dalam kabin mobil dan radiasi dari sinar matahari terhadap kaca mobil serta pantulan radiasi oleh interior di dalam mobil. Untuk mengatasi peningkatan temperatur di dalam 
kabin maka dirancang sebuah pendingin kabin mobil berbasis termoelektrik. Pendingin kabin mobil berbasis termoelektrik tersebut memiliki dua sisi yaitu sisi panas dan sisi dingin dengan sumber listrik dari accu. Dengan demikian diharapkan pendingin kabin mobil berbasis termoelektrik dapat mengurangi temperatur panas di didalam kabin mobil. Hasil penelitian menunjukkan bahwa penggunaan pendingin kabin mobil berbasis termoelektrik ini dapat menurunkan temperatur hingga $48^{\circ} \mathrm{C}$ (Priyambada 2012).

Desain peltier refrigerant berkembang melalui serangkaian langkah-langkah (Awasthi and Mali 2012). Langkah-langkah ini adalah identifikasi masalah, menganalisis masalah, brainstorming ide-ide, memutuskan pilihan desain, dan menerapkan desain. Mendesain ulang jika perlu. Pertimbangan desain utama adalah metode transfer panas, geometri dan material (Awasthi and Mali 2012).

Sebuah sistem pendingin dan pemanas udara termoelektrik dirancang dan dibangun untuk dapat digunakan pada pendinginan dan pemanasan (Totala et al. 2014). Empat TEC digunakan untuk pendinginan dengan catu daya DC melalui power supply eksternal. Hasil pengujian menunjukkan bahwa sistem pendingin mampu mendinginkan dan memanaskan udara ketika udara disirkulasikan dengan bantuan blower. TEC dirancang mampu mendinginkan suhu udara ruangdari $32,5^{\circ} \mathrm{C}$ menjadi $22,1^{\circ} \mathrm{C}$. Pendinginan stabil dalam waktu sepuluh menit setelah blower dinyalakan (dengan kecepatan 2,5 m/s). Sistem ini dapat mencapai perbedaan suhu target yang ditetapkan yaitu $6^{\circ} \mathrm{C}$. Semua komponen dalam proyek telah diuji secara individual dan hasilnya positif. Prototipe dapat dibuat ringkas dengan memilih TEC tunggal berkekuatan lebih tinggi (contohnya $200 \mathrm{~W}$ atau lebih). Hal ini dapat dilakukan dengan memilih heat sink yang lebih baik pada sisi dingin yang memiliki saluran atau pipa yang dapat mensirkulasi udara lebih lama. Ini dilakukan sebagai alternatif untuk penggunaan kipas aksial seperti dalam proyek ini, jika digunakan kipas blower maka akan memberikan aliran udara yang lebih baik. Heat sink lebih besar pada sisi panas harus dipilih secara akurat berdasarkan perhitungan resistensi termal untuk efisiensi pendinginan terbaik. Dengan TEC tunggal, satu heat sink pada sisi panas dan sisi dingin, sebuah pendingin mini yang memberikan kenyamanan dapat dibuat dan dapat diinstal pada atap untuk pendingin individu dengan mengubah aliran udara dan beberapa modifikasi mekanik atau elektronik, pendingin udara TEC untuk mobil dapat juga digunakan untuk pemanas.

Studi telah dilakukan untuk mengkaji perkembangan terkini bahan termoelektrik, pendekatan pemodelan, dan aplikasi (Zhao and Tan 2014). Sistem pendingin termoelektrik memiliki keunggulan dibandingkan perangkat pendingin konvensional, termasuk ringkas dalam ukuran, ringan, kehandalan yang tinggi, tidak ada bagian mekanik yang bergerak, tidak ada fluida yang bekerja, menggunakan arus searah, dan dengan mudah beralih fungsi sebagai pendingin dan pemanas. Untuk meningkatkan kinerja termoelektrik sistem pendingin, teknik pemodelan telah dideskripsikan baik untuk pemodelan termoelemen dan pendingin termoelektrik (TEC), termasuk model energi ekuilibrium standar yang disederhanakan, model satu dimensi dan tiga dimensi, dan model numerik compact.Aplikasi pendingin TEC dikaji pada aspek pendingin domestik, pendingin elektronik, aplikasi ilmiah, dan AC mobil dan kontrol suhu kursi, dengan ringkasan untuk modul termoelektrik dan pendingin termoelektrik yang tersedia secara komersial.

Sistem AC saat ini menghasilkan efek pendinginan dengan refrigeran seperti freon, amonia, dan lain-lain. Penggunaan refrigeran ini bisa mendapatkan output maksimum namun memiliki kelemahan utama yaitu emisi gas berbahaya dan pemanasan global. Masalah ini dapat diatasi dengan menggunakan pendingin udara berbasis thermoelectric (efek Peltier), dan modul ini melindungi lingkungan. Makalah ini membahas AC termoelektrik dengan menggunakan berbagai modul yang berbeda.

Sistem pendingin termoelektrik memiliki 
keunggulan dibandingkan perangkat pendinginan konvensional, seperti compact dalam ukuran, ringan, kehandalan yang tinggi, tidak ada bagian mekanik yang bergerak dan tidak ada fluida yang bekerja (Benziger, Anu, and Balakrishnan 2015).

Perancangan sistem pendingin air menggunakan elemen Peltier berbasis mikrokontroler ATmega8535 telah dilakukan (Gandi and Yusfi 2016). Sisi dingin elemen Peltier dimanfaatkan sebagai pendingin air. Kemampuan elemen Peltier untuk memompa panas dari sistem ke lingkungan diuji dengan menvariasikan massa air yaitu $50 \mathrm{~g}, 100 \mathrm{~g}, 150$ g, $300 \mathrm{~g}$ dan $500 \mathrm{~g}$. Panas dari sistem diserap melalui heatsink bagian bawah kemudian panas dilepaskan ke lingkungan pada heatsink bagian atas. Fan AC digunakan untuk mempercepat pelepasan panas dari heatsink ke udara sehingga pemindahan panas dari sistem ke lingkungan berjalan lebih cepat. Sensor LM35 digunakan sebagai pendeteksi perubahan temperatur. Mikrokontroler ATmega8535 memproses keluaran sensor LM35 dan menampilkannya di LCD. Hasil penelitian menunjukkan kemampuan elemen Peltier menurun seiring bertambahnya massa air dan meningkat dengan bertambahnya tegangan dan arus. Pada tegangan $12 \mathrm{~V} / 3 \mathrm{~A}$, elemen Peltier mampu menurunkan temperatur air bermassa $50 \mathrm{~g}$ hingga $5,7^{\circ} \mathrm{C}$, sedangkan untuk air bermassa $500 \mathrm{~g}$ elemen Peltier hanya mampu menurunkan temperatur air hingga $14,2{ }^{\circ} \mathrm{C}$.

\section{METODOLOGI}

Media kalibrasi thermohygrometer berukuran $970 \mathrm{~mm}$ x $630 \mathrm{~mm}$ x $542 \mathrm{~mm}$ Media yang digunakan ditunjukkan pada Gambar 1.

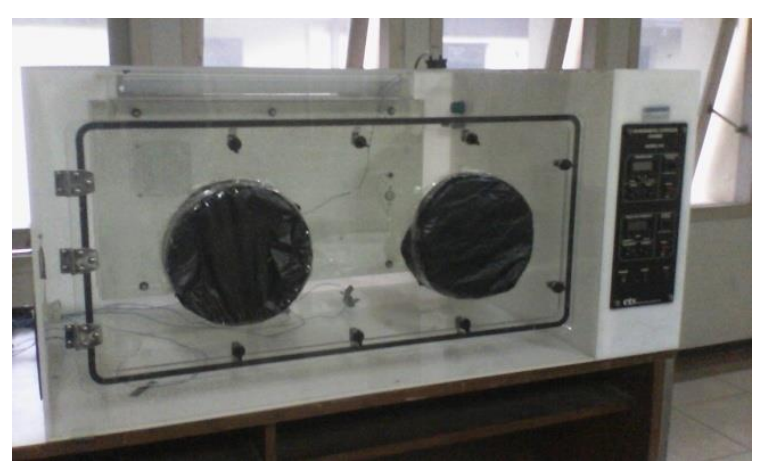

Gambar 1. Media kalibrasi thermohygrometer

Penelitian ini menggunakan bahan sebagai berikut (Gambar 2a sampai 2e)

- $\quad 5$ buah peltier $5 \mathrm{~V}$ ukuran $3 \mathrm{~cm} \times 1,5 \mathrm{~cm}$ (Peltier ET-063-10-13)

- $\quad 3$ buah peltier $12 \mathrm{~V}$ ukuran $4 \mathrm{~cm} \mathrm{x} 4 \mathrm{~cm}$ (Peltier ET-127-14-11)

- Kipas

- $\quad$ Heat sink (A: 46 x 41 x 12 mm; B: 78 x 65 × $30 \mathrm{~mm} \& \mathrm{C}: 145 \times 62 \times 20 \mathrm{~mm})$

- $\quad$ Radiator (A:105 x 81 x 25 mm; B:600 x 313 x $23 \mathrm{~mm}$ dan C: $162 \times 41 \times 12 \mathrm{~mm})$

- Pompa

- Coolant

- Thermal paste

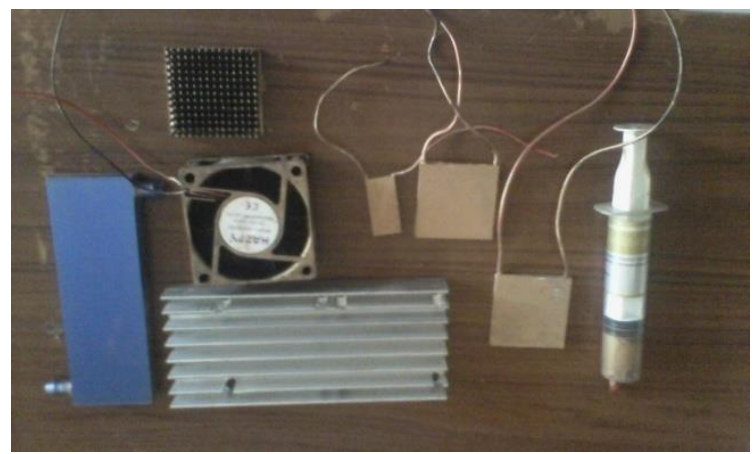

Gambar 2a. Radiator C, kipas, heat sink, peltier dan thermal paste

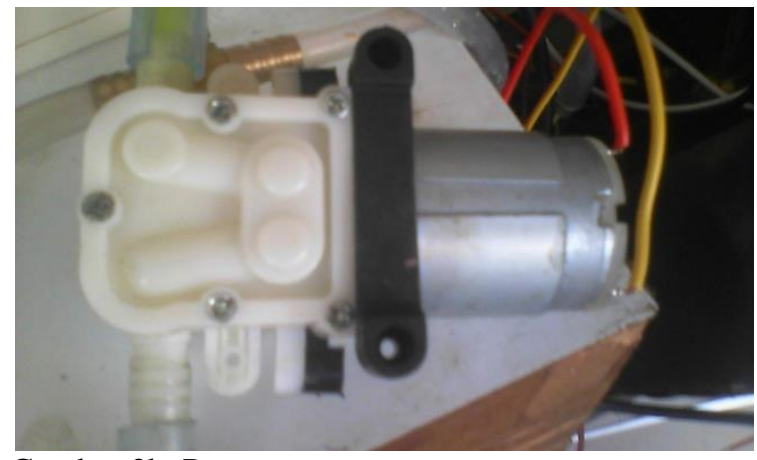

Gambar 2b. Pompa 


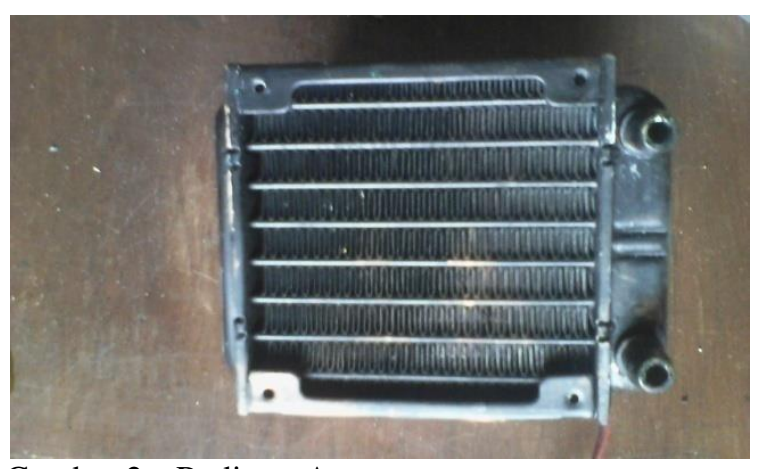

Gambar 2c. Radiator A

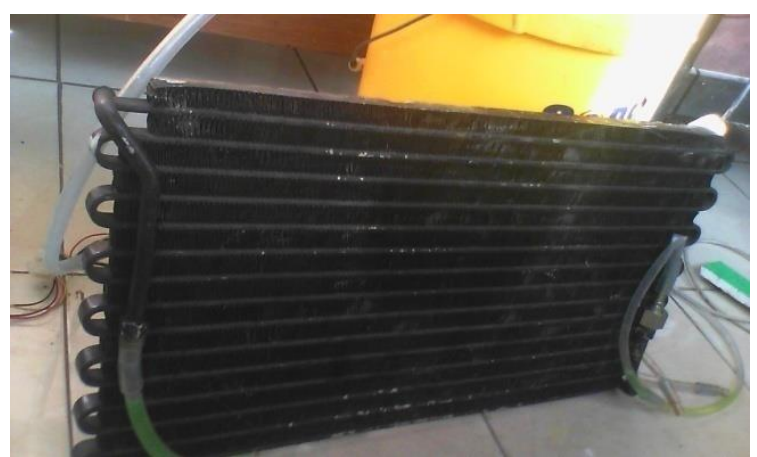

Gambar 2d. Radiator B

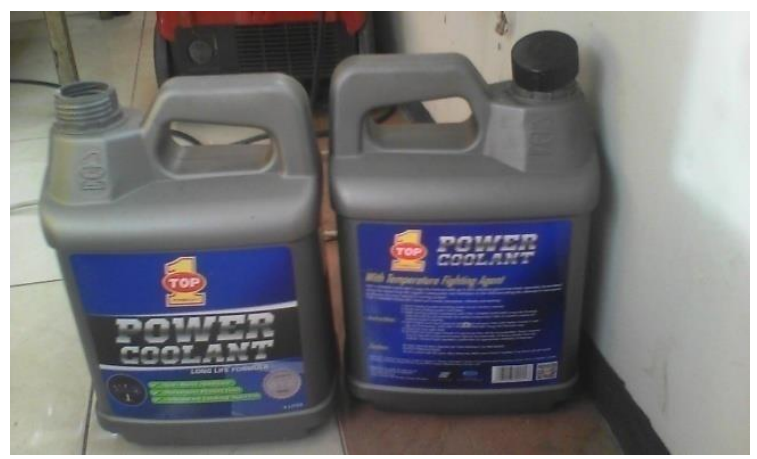

Gambar 2e. Coolant

Alat ukur Data Acquisition yang dilengkapi termokopel (Gambar 3)

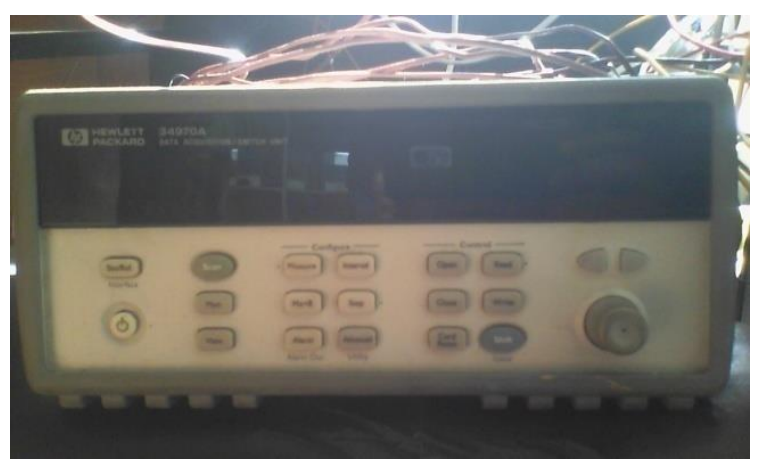

Gambar 3. Alat ukur temperatur

Diagram blok tahapan penelitian ditunjukkan pada Gambar 4.

Perhitungan beban termal dilakukan dengan menggunakan data Tabel 1 dan Tabel 2 .

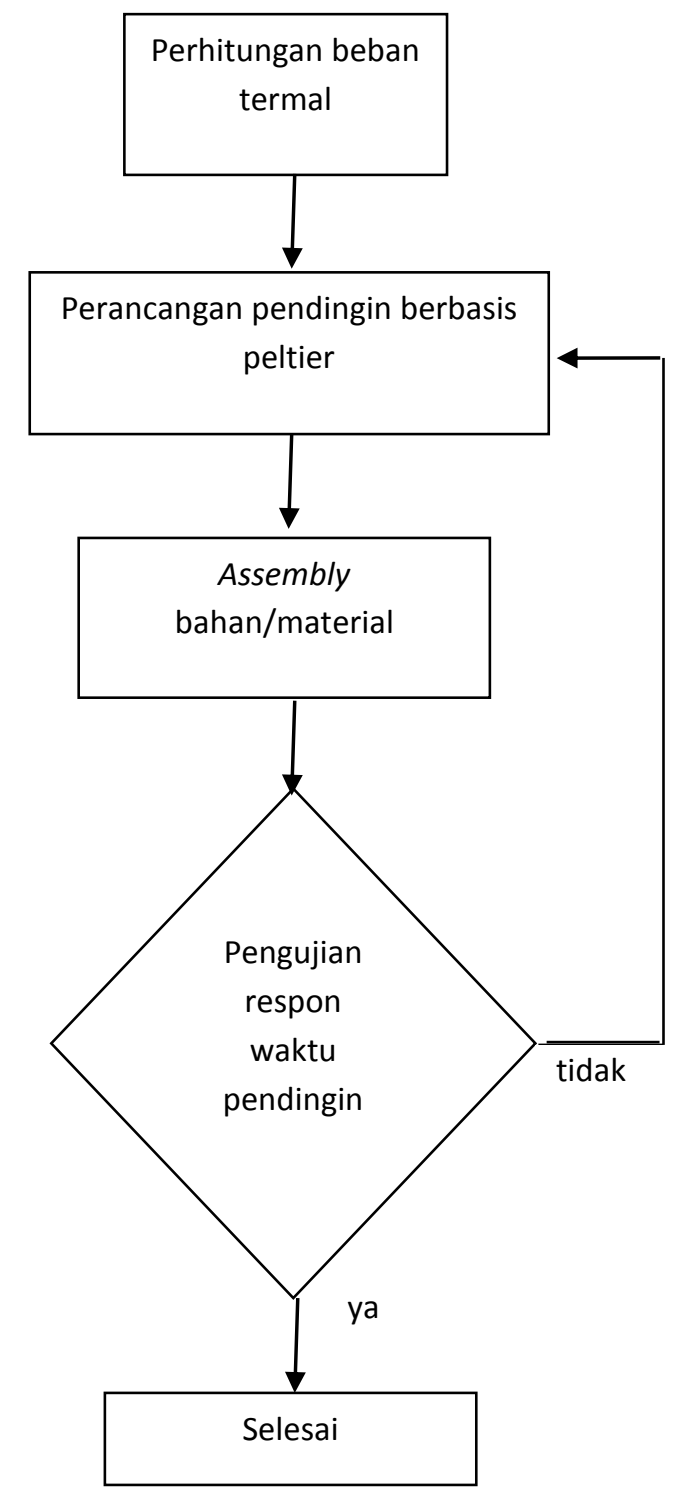

Gambar 4. Diagram blok penelitian

Tabel 1. Spesifikasi media

Parameter Nilai

METAL INDONESIA Vol. 39 No. 2 Desember 2017 (86-94) 


\begin{tabular}{|c|c|c|}
\hline Dimensi luar media(mm) & $\begin{array}{l}\text { Panjang } \\
\text { Lebar } \\
\text { Tinggi }\end{array}$ & $\begin{array}{l}978 \\
638 \\
548\end{array}$ \\
\hline Dimensi dalam media $(\mathrm{mm})$ & $\begin{array}{l}\text { Panjang } \\
\text { Lebar } \\
\text { Tinggi }\end{array}$ & $\begin{array}{l}970 \\
630 \\
542\end{array}$ \\
\hline Dimensi plat besi(mm) & $\begin{array}{l}\text { Panjang } \\
\text { Lebar } \\
\text { Tinggi }\end{array}$ & $\begin{array}{l}922 \\
1,5 \\
590\end{array}$ \\
\hline
\end{tabular}

Tabel 2. Beban panas

\begin{tabular}{|l|l|l|}
\hline \multicolumn{2}{|c|}{ Parameter } & Nilai \\
\hline Temperatur dalam, $\mathrm{Td}\left({ }^{\circ} \mathrm{C}\right)$ & & 20 \\
\hline Temperatur luar, Tl $\left({ }^{\circ} \mathrm{C}\right)$ & & 27 \\
\hline Tebal material (mm) & $\begin{array}{l}\text { Acrylic } \\
\text { Besi }\end{array}$ & 8 \\
\hline $\begin{array}{l}\text { Konduktivitas } \\
\left.\text { termal ,k(W/m. }{ }^{\circ} \mathrm{C}\right)\end{array}$ & $\begin{array}{l}\text { Acrylic } \\
\text { Besi }\end{array}$ & 0,2 \\
\hline $\begin{array}{l}\text { Koefisien transfer } \\
\text { panas,h, }\left(\mathrm{W} / \mathrm{m}^{2} .{ }^{\circ} \mathrm{C}\right)\end{array}$ & udara & 80 \\
\hline
\end{tabular}

*(Varghese et al. 2016)

Beban termal dalam sistem media kalibrasi thermohygrometer diasumsikan beban termal pasif saja. Beban termal pasif media terdiri dari transfer panas konduksi dan konveksi(Varghese et al. 2016)

$Q=\frac{\Delta T \cdot A}{\frac{1}{h}+\frac{l}{k}}$

Dimana:

$$
\begin{aligned}
Q & : \text { beban termal }(\mathrm{W}) \\
\Delta T & : \text { perbedaan temperatur } \\
& \text { terhadaptemperatur media }\left({ }^{\circ} \mathrm{C}\right) \\
A & : \text { luas perpindahan panas }\left(\mathrm{m}^{2}\right) \\
h & : \text { koefisien transfer panas }\left(\mathrm{W} / \mathrm{m}^{2} .{ }^{\circ} \mathrm{C}\right) \\
l & : \text { tebal material }(\mathrm{m})
\end{aligned}
$$

Luas permukaan transfer panas media kalibrasi thermohygrometer dibagi menjadi 6 , yaitu dinding depan $\left(A_{a}\right)$, belakang $\left(A_{b}\right)$, sisi kanan $\left(A_{c}\right)$,sisi kiri $\left(A_{d}\right)$, atas $\left(A_{e}\right)$ dan bawah $\left(A_{f}\right)$. Beban panas total $(\mathrm{Q})$ dihitung dengan persamaan:

$Q=Q_{a}+Q_{b}+2 Q_{c}+2 Q_{e}$
Dimana:

$Q_{a} \quad$ : Beban termal dinding depan (W)

$Q_{b} \quad$ : Beban termal dinding belakang (W)

$Q_{c}=Q_{d}:$ Beban termal dinding sisi kanan/kiri (W)

$Q_{e}=Q_{f}:$ Beban termal dinding atas/bawah (W)

Temperatur sisi panas peltier (Varghese et al. 2016)

$T_{h}=T_{a}+(V I+Q) R_{Q}$

Dimana:

$T_{h}$ : temperature sisi panas peltier $\left({ }^{\circ} \mathrm{C}\right)$

$T_{a}$ : temperatur ruangan $\left({ }^{\circ} \mathrm{C}\right)$

Temperatur sisi panas $\left(T_{h}\right)$ dibatasi 15 ${ }^{\circ} \mathrm{C}$ diatas temperatur ruang(Varghese et al. 2016).

Temperatur media diukur berdasarkan perhitungan temperatur kalibrasi enclosure("Australian Standard ( ${ }^{\circledR}$ Enclosures - "1986)

$\mathrm{T}_{\text {media }}=\left(\mathrm{T}_{\max }+\mathrm{T}_{\min }\right) / 2$

Dimana:

$T_{\text {media }}$ : temperatur media

$T_{\max }:$ temperatur indikator maksimum $\left({ }^{\circ} \mathrm{C}\right)$

$T_{\min } \quad$ : temperatur indikator minimum $\left({ }^{\circ} \mathrm{C}\right)$ Posisi termokopel dalam penelitian ini ditunjukkan pada Gambar 5(“Australian Standard ® Enclosures — " 1986)

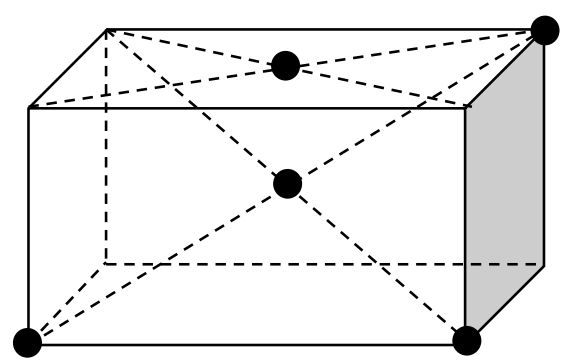

Ket: Posisi termokopel

Gambar 5. Posisi termokopel di media kalibrasi thermohygrometer

Tabel 3 dan 4 menunjukkan spesifikasi peltier 
yang digunakan untuk berbagai konfigurasi perancangan.

Tabel 3. Spesifikasi Peltier ET-061-10-13

\begin{tabular}{|l|c|}
\hline Parameter & Nilai \\
\hline$I \max (\mathrm{A})$ & 3,9 \\
\hline $\max (\mathrm{Vdc})$ & 7,8 \\
\hline$P \max (\mathrm{W})$ & 19 \\
\hline$\Delta \operatorname{Tmax}\left({ }^{\circ} \mathrm{C}\right)$ & 74 \\
\hline$A(\mathrm{~mm})$ & 30 \\
\hline$A I(\mathrm{~mm})$ & 30 \\
\hline$B(\mathrm{~mm})$ & 15 \\
\hline$H(\mathrm{~mm})$ & 3,6 \\
\hline$L(\mathrm{~mm})$ & 100 \\
\hline Wire $(\mathrm{AWG})$ & n/a \\
\hline
\end{tabular}

* (Sisi panas $T h=25{ }^{\circ} \mathrm{C} / 298 \mathrm{~K}$, dengan pengering $\mathrm{N}_{2}$ )

* Pcmax = daya pendinginan pada $\Delta T=0$ dan $I=\operatorname{Imax}$

$* \Delta \operatorname{Tmax}=$ perbedaan temperatur pada $I=I \max$

*Temperatur sisi panas $T h=90{ }^{\circ} \mathrm{C}$ untuk performansi terbaik yang lama

*Tekanan max Mounting 1,5 Mpa

*Wires UL style 1569, $105 \circ C$ (unstripped)

Sumber : docs-asia.electrocomponents.com

Tabel 5. Spesifikasi Peltier ET-127-14-11

\begin{tabular}{|l|c|}
\hline Parameter & Nilai \\
\hline$I \max (\mathrm{A})$ & 8,5 \\
\hline $\operatorname{Vmax}(\mathrm{Vdc})$ & 15,7 \\
\hline$P \max (\mathrm{W})$ & 77,1 \\
\hline$\Delta \operatorname{Tmax}\left({ }^{\circ} \mathrm{C}\right)$ & 72 \\
\hline$A(\mathrm{~mm})$ & 40 \\
\hline$A I(\mathrm{~mm})$ & 40 \\
\hline$B(\mathrm{~mm})$ & 40 \\
\hline$H(\mathrm{~mm})$ & 3,8 \\
\hline$L(\mathrm{~mm})$ & 100 \\
\hline Wire $(\mathrm{AWG})$ & n/a \\
\hline
\end{tabular}

* (Sisi panas $T h=25{ }^{\circ} \mathrm{C} / 298 \mathrm{~K}$, dengan pengering $\mathrm{N}_{2}$ )

* Pcmax = daya pendinginan pada $\Delta T=0$ dan $I=\operatorname{Imax}$

$* \Delta \operatorname{Tmax}=$ perbedaan temperatur pada $I=\operatorname{Imax}$

*Temperatur sisi panas $T h=90{ }^{\circ} \mathrm{C}$ untuk performansi terbaik yang lama

*Tekanan max Mounting 1,5 Mpa

*Wires UL style 1569, $105{ }^{\circ} \mathrm{C}$ (unstripped)

Sumber : docs-asia.electrocomponents.com

Geometri peltier ET-063-10-13 dan ET-12714-11 ditunjukkan Gambar 6 dan 7.

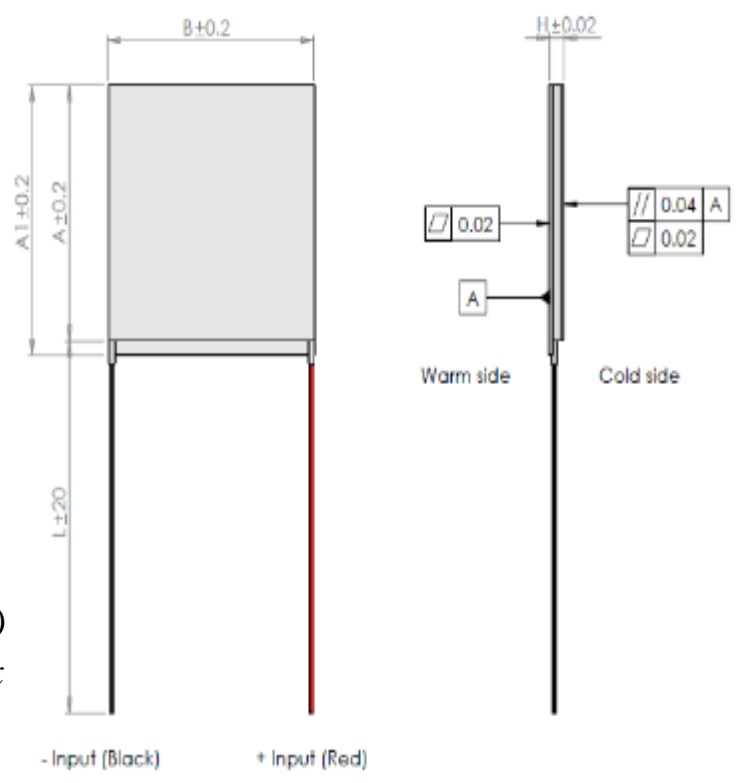

Gambar 6. Peltier ET-063-10-13(http://docsasia.electrocomponents.com)

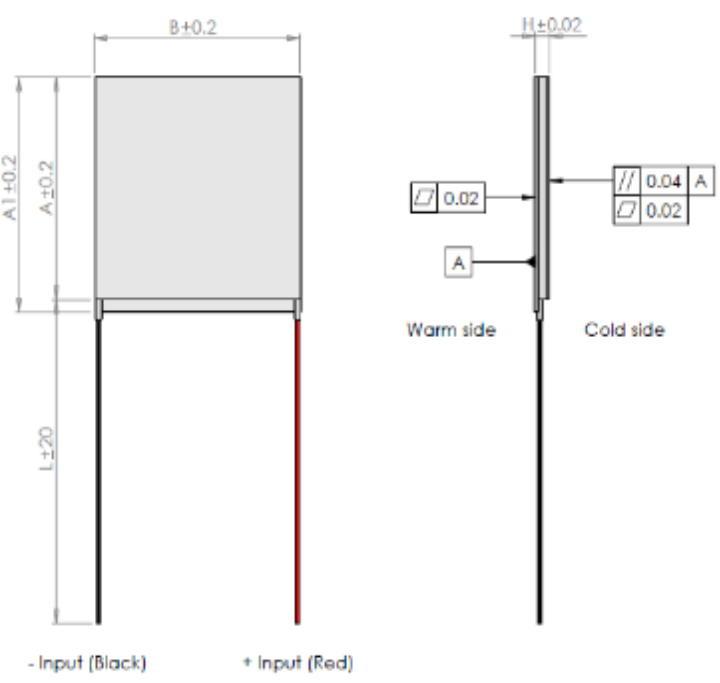

Gambar 7. Peltier ET-127-14-11 (http://docs- 
asia.electrocomponents.com)

Hasil perhitungan beban termal digunakan untuk merancang dan assembly pendingin dengan berbagai konfigurasi.

\section{HASIL DAN PEMBAHASAN}

Berdasarkan data Tabel I dan II, beban termal media kalibrasi thermohygrometer ditunjukkan pada Tabel V.

Tabel 5. Beban termal perpindahan panas dinding media kalibrasi thermohygrometer

\begin{tabular}{|l|l|l|l|}
\hline \multicolumn{1}{|c|}{$\begin{array}{c}\text { Dinding } \\
\text { Media }\end{array}$} & Material & $\begin{array}{c}\text { Luas } \\
\mathbf{A}\left(\mathbf{m}^{2}\right)\end{array}$ & $\mathbf{Q}(\mathbf{W})$ \\
\hline Depan & acrylic & 0,52 & 26,29 \\
\hline Belakang & acrylic plat $^{*}$ & 0,20 & 9,90 \\
& besi $^{*}$ & 0,33 & 16,38 \\
\hline Kanan/kiri & acrylic & 0,34 & 34,15 \\
\hline Atas/Bawah & acrylic & 0,61 & 61,11 \\
\hline Beban Thermal total & 147,83 \\
\hline
\end{tabular}

*asumsi

Untuk keamanan digunakan toleransi beban termal tambahan senilai 30\% dari beban hasil perhitungan. Dengan demikian beban termal total yang diperhitungkan senilai 192,18 W.

Sistem pendingin berbasis peltier dirancang untuk mengetahui kemampuan pendinginan tiap konfigurasi rancangan. Rancangan disusun menjadi 4 konfigurasi A, B, C, dan D. Thermal paste digunakan untuk pelapis antara heat sink dengan peltier sisi dingin dan radiator dengan peltier sisi panas. Coolant dialirkan pompa dari wadah ke radiator pertama dan disedot pompa untuk dialirkan ke radiator kedua dan keluar ke wadah. Radiator pertama yang dimaksud adalah radiator yang terkoneksi dengan sisi panas peltier dan radiator kedua adalah radiator yang menerima keluaran coolant dari radiator pertama.

Konfigurasi A ditunjukkan di Gambar 8.

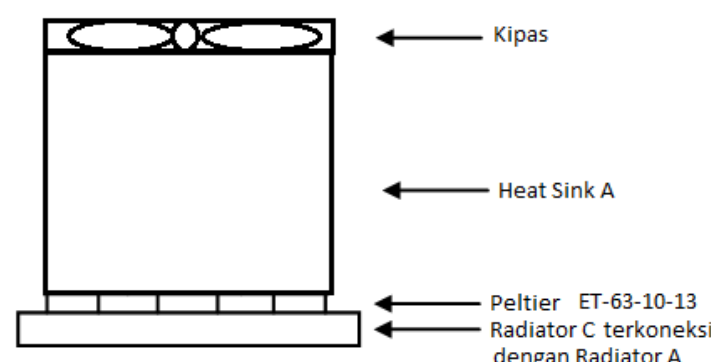

Gambar 8. Konfigurasi A

Dari proses pengujian diperoleh data grafik respon temperatur terhadap waktu (Gambar 9).

\section{Respon temperatur terhadap waktu}

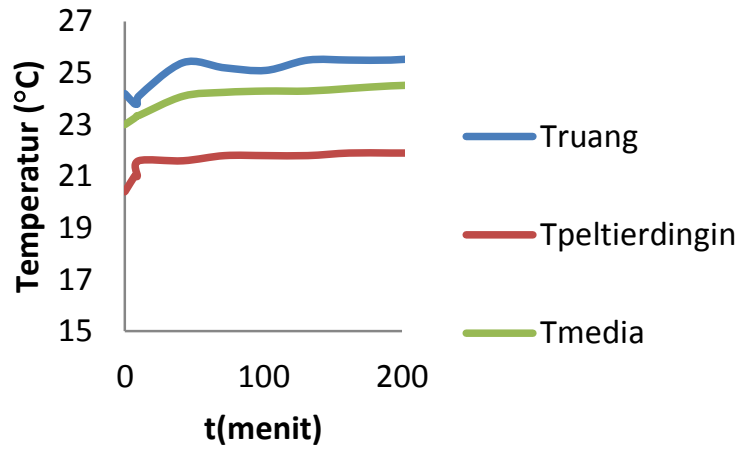

Gambar 9. Grafik respon temperatur terhadap waktu untuk konfigurasi sistem pendingin $\mathrm{A}$

Pendingin konfigurasi A mampu mendinginkan media sampai temperatur $24,55{ }^{\circ} \mathrm{C}$ dalam waktu 221 menit dengan temperatur ruangan $25,6^{\circ} \mathrm{C}$. Data menunjukkan bahwa temperatur ruangan mempengaruhi temperatur media kalibrasi thermohygrometer.

Pendingin konfigurasi B ditunjukkan Gambar 10.

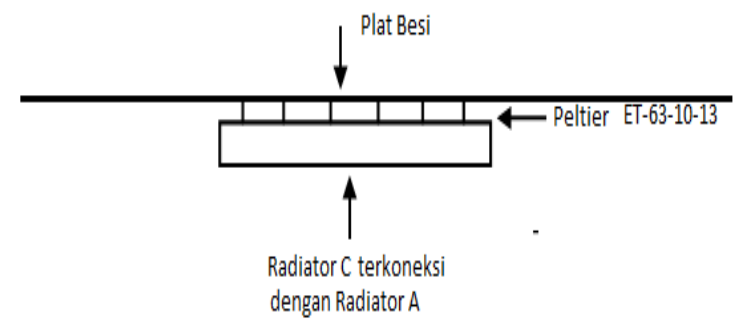

Gambar 10. Konfigurasi pendingin B

Heat sink pada sisi dingin peltier berupa plat 
besi pada dinding belakang media kalibrasi thermohygrometer.

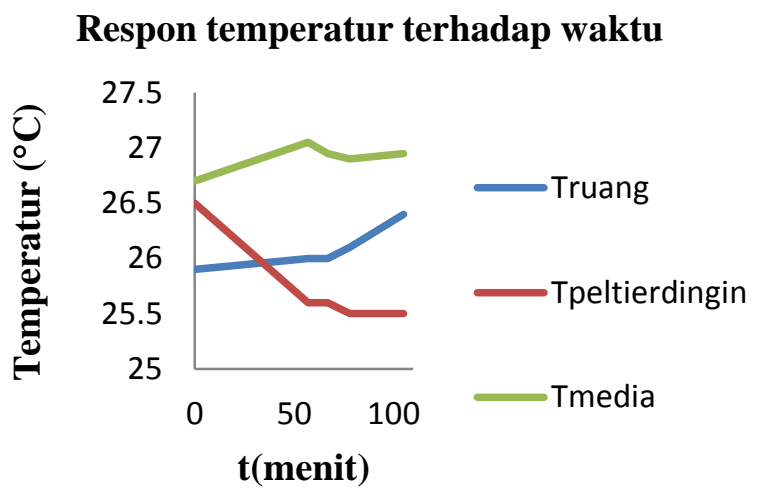

Gambar 11. Grafik respon temperatur terhadap waktu untuk konfigurasi sistem pendingin B

Media kalibrasi thermohygrometer dengan konfigurasi sistem pendingin $\mathrm{B}$ mencapai temperatur $26,95^{\circ} \mathrm{C}$ dalam waktu 105 menit dengan temperatur ruangan $26,4^{\circ} \mathrm{C}$. Temperatur media dengan pendingin konfigurasi B menunjukkan bahwa temperatur ruangan masih mempengaruhi temperatur media kalibrasi thermohygrometer.

Konfigurasi pendingin selanjutnya adalah konfigurasi C seperti ditunjukkan pada Gambar 12.

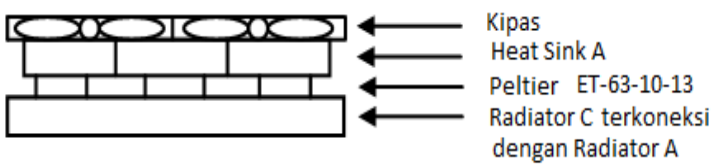

Gambar 12. Konfigurasi pendingin C

Hasil pengujian konfigurasi pendingin $\mathrm{C}$ ditunjukkan pada Gambar 13.

\section{Respon temperatur terhadap waktu}

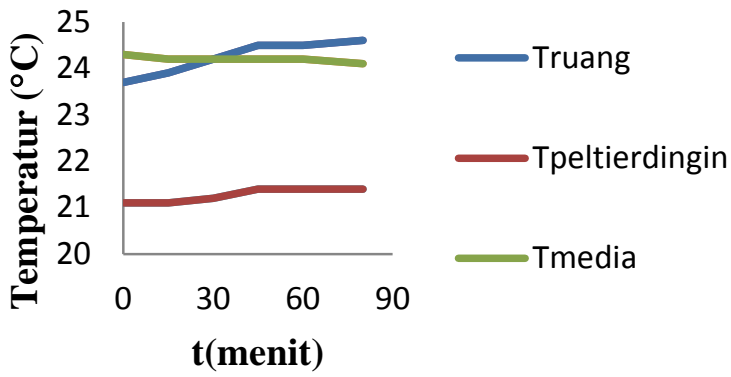

Gambar 13. Grafik respon temperatur terhadap waktu untuk pendingin konfigurasi $\mathrm{C}$

Dalam waktu 80 menit, media kalibrasi thermohygrometer mencapai temperatur $24,1^{\circ} \mathrm{C}$ pada temperatur ruangan $24,6{ }^{\circ} \mathrm{C}$. Data menunjukkan bahwa kerja sistem pendingin tidak maksimal, ini dikarenakan waktu pendinginan sebentar.

Selanjutnya pendingin kofigurasi $\mathrm{D}$ diassembly dan dilakukan pengujiannya. Gambar 14 menunjukkan pendingin konfigurasi D.

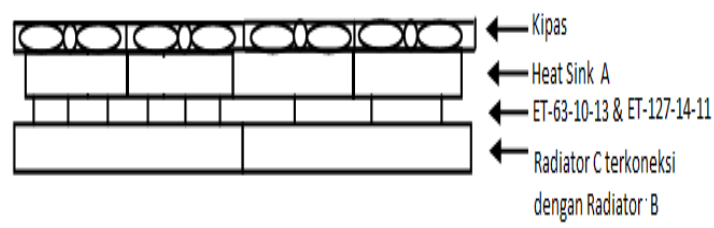

Gambar 14. Konfigurasi pendingin D

Hasil pengujian ditunjukkan pada Gambar 15.

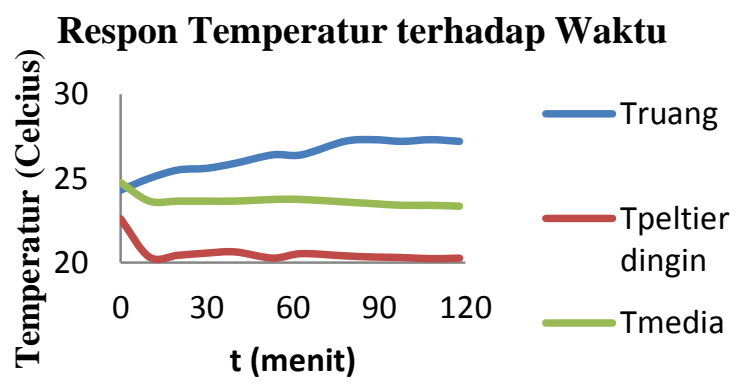

Gambar 15. Grafik respon temperatur terhadap waktu untuk pendingin konfigurasi D

Pada saat pengujian temperatur sisi dingin peltier menurun dari temperatur $22,6^{\circ} \mathrm{C}$ sampai $20,3^{\circ} \mathrm{C}$. Temperatur ruangan awal $24,3^{\circ} \mathrm{C}$ naik 
sampai $27,{ }^{\circ} \mathrm{C}$. Temperatur media kalibrasi thermohygrometer awal $24,8^{\circ} \mathrm{C}$ dan mencapai temperatur $23,4^{\circ} \mathrm{C}$ dengan waktu uji 118 menit dan temperatur ruangan $27,2^{\circ} \mathrm{C}$.

\section{KESIMPULAN DAN SARAN}

Rancangan sistem pendingin media berbasis peltier dilakukan sebanyak empat konfigurasi yaitu konfigurasi A, B, C, dan D. Hasil pengujian pendingin keempat konfigurasi diperoleh bahwa konfigurasi D menghasilkan temperatur media terendah. Konfigurasi ini terdiri dari radiator $\mathrm{C}$ yang terhubung dengan Radiator B, 5 modul peltier ET-63-10-13 dan 3 modul peltier ET-127-14-11, heat sink A dan kipas mampu mencapai suhu terendah yaitu $23,4^{\circ} \mathrm{C}$ dengan temperatur ruangan $27,2^{\circ} \mathrm{C}$ dalam waktu 118 menit. Kenaikan temperatur ruangan tidak mempengaruhi kenaikan temperatur media kalibrasi thermohygrometer.

Konfigurasi pendingin A, B, dan C menggunakan 5 modul peltier yang spesifikasinya belum cukup memenuhi beban termal. Secara ideal konfigurasi D ini cukup untuk mengatasi beban termal pada temperatur media $20^{\circ} \mathrm{C}$ tetapi dalam pengujian riil spesifikasi peltier dan konfigrasi pendingin belum cukup untuk mencapai temperatur tersebut karena pendinginan sisi panas peltier belum optimal dan kemungkinan adanya beban termal komponen lain yang belum diperhitungkan.

Parameter yang menentukan temperatur media kalibrasi thermohygrometer antara lain adalah material media dan komponen yang ada didalamnya, dimensi material, konduktivitas thermal material, dan juga koefisien transfer panas.

Untuk mencapai temperatur $20^{\circ} \mathrm{C}$ pada media kalibrasi thermohygrometer dengan volume tetap, maka perlu adanya penambahan modul pendingin peltier dan optimasi pendinginan pada sisi panas modul peltier.
Penulis mengucapkan terima kasih kepada Kepala Balai Besar Logam dan Mesin, Bapak Eddy Siswanto yang telah memfasilitasi pelaksanaan penelitian ini.

\section{DAFTAR PUSTAKA}

1. "Australian Standard ${ }^{\circledR}$ Enclosures -." 1986.

2. Awasthi, Mayank, and K V Mali. 2012. "Design and Development of Thermoelectric Refrigerator." Int. J. Mech. Eng. \& Rob. Res 1 (3). http://www.ijmerr.com/uploadfile/2015/040 9/20150409025007549.pdf.

3. Benziger, Anu, and Balakrishnan. 2015. "Review Paper on Thermoelectric AirConditioner Using Peltier Modules." International Journal of Mechanical Engineering (IJME) 4 (3): 49-56. http://www.iaset.us/view_archives.php?yea $\mathrm{r}=2015 \& \mathrm{jtype}=2 \& \mathrm{id}=67 \&$ details $=$ archives .

4. Gandi, Frima, and Meqorry Yusfi. 2016 "Berbasis Mikrokontroler ATmega8535." Jurnal Fisika Unand 5 (1): 35-41.

5. Priyambada, Sandya. 2012. "PENDINGIN KABIN MOBIL.” Skripsi Universitas Indonesia.

6. Totala, Desai, Singh, Gangopadhyay, Yaqub, and Jane. 2014. "Study and Fabrication of Hermoelectric Air Cooling and Heating System." International Journal of Engineering Inventions 4 (2): 20-30. http://www.ijeijournal.com/papers/Vol.4Iss.2/D04022030.pdf.

7. Varghese, Antony, Ashish Achankunju, Rejo Mathew, and Renchi George. 2016. "Design and Fabrication of Thermoelectric Refrigerator with Thermosiphon System." International Journal of Scientific Engineering and Applied Science, no. 24: 2395-3470. www.ijseas.com.

8. Zhao, Dongliang, and Gang Tan. 2014. “A Review of Thermoelectric Cooling: Materials, Modeling and Applications." Applied Thermal Engineering. doi:10.1016/j.applthermaleng.2014.01.074.

\section{UCAPAN TERIMA KASIH}

